\title{
Innovadores, adaptaciones creativas y proyectos "nacionales". \\ La circulación de ideas en las ciencias sociales argentinas (1950-1976)
}

\author{
Gastón Julián Gil ${ }^{1}$ \\ CONICET- Universidad Nacional de Mar del Plata
}

\section{Resumen}

Entre las décadas de 1950 y 1970 las ciencias sociales argentinas experimentaron un pluralismo teórico que combinó diversos procesos de espacialización de teorías provenientes de los centros metropolitanos de producción de conocimiento. Esas adaptaciones, más o menos creativas, convivieron con propuestas de formular teorías endógenas guiadas por un compromiso militante y el afán de transformación social. En el marco de su definitiva institucionalización, disciplinas como antropología y sociología tuvieron referentes académicos que, en general desde sus anclajes institucionales, marcaron el pulso de las discusiones teóricas, en muchos casos atravesados por la coyuntura política. Aunque los legados que dejaron esos cientistas sociales para el devenir de cada una de las disciplinas fue dispar, constituyen una marca indeleble de como se practicaban las ciencias sociales en la Argentina y de los conflictos que dominaron el campo de las ciencias sociales durante tres décadas.

\section{Palabras clave}

\section{Antropología de la ciencia - Creatividad - Innovación - Argentina}

\footnotetext{
${ }^{1}$ Gastón Julián Gil es doctor en antropología Social (UNaM), investigador independiente del CONICET y profesor de grado y postgrado en la Universidad Nacional de Mar del Plata. En los últimos diez años realizó estudios de antropología histórica sobre la conformación de los campos disciplinares en las ciencias sociales argentinas entre las décadas de 1950, 1960 y 1970. Sobre esas investigaciones publicó Universidad y Utopía (EUDEM, 2010) y Las sombras del Camelot (EUDEM, 2011).
} 


\begin{abstract}
Between the decades of 1950 and 1970 social sciences in Argentina experienced a theoretical pluralism that combined several processes of spatialization of theories that came from metropolitan centers of knowledge production. Such adaptations, which were relatively creative, coexisted with proposals of endogenous theories that should be guided by political commitment and the ideal of social transformation. Within the context of their definitive institutionalization, disciplines like anthropology or sociology found academic referents that, mostly linked to their own institutions, led the way in theoretical discussions, in many cases determined by the political situation. Although the legacy of such social scientists showed many differences, it is an indelible mark of the ways in which social sciences were practiced in Argentina and of the conflicts that were predominant in the field of social sciences for three decades.
\end{abstract}

\title{
Key Words
}

Anthropology of science - Creativity - Innovation- Argentina

\section{Innovación y creatividad en la ciencia}

La innovación y la creatividad constituyen dos de los valores más amplia y positivamente reconocidos en la ciencia. Sin embargo, no se trata de procesos lineales o sencillos de discriminar, entre otras razones porque se los suele utilizar como sinónimos. E igualmente complejo es determinar el grado de innovación y creatividad que pueda mostrar una trayectoria académica. De manera preliminar, puede plantearse que la creatividad suele asociarse a la concepción de nuevas ideas (en nuestro caso referido a, por ejemplo, un modo particular de abordaje de lo social), conceptos novedosos, entre otras posibilidades. Aunque la línea que los separa es bastante sutil, la innovación comúnmente se vincula con la capacidad de aplicar y combinar ideas de manera novedosa, lo cual en el ámbito académico excede ampliamente la reflexión teórica o la producción académica escrita. Si se 
acepta esta separación, la historia de todo campo científico nos mostrará actores académicos con una gran capacidad de innovación (por ejemplo institucional) pero que no necesariamente se destacan o deslumbran por su creatividad. Como contrapartida, no pocos académicos creativos necesariamente producirán innovaciones significativas o generarán un impacto evidente en sus campos disciplinares, y tal vez sus legados puedan llegar a perderse entre sus contemporáneos. Por supuesto, aunque se trate de casos excepcionales, algunos actores alcanzan elevados estándares en ambas dimensiones, que claro está son sumamente complejas de mensurar.

Todo parece indicar que la capacidad de innovación ofrece mayores posibilidades para ser mensurada, dado que la creatividad remitiría a aspectos cualitativamente diferentes y que produce huellas diferenciales en el tiempo. Lo que sí ambas dimensiones generan es una ruptura con el sentido común académico. De hecho, suele afirmarse que existe una «tensión esencial» entre tradición e innovación (o conformidad y disenso), que constituye una clásica inquietud de la epistemología de Thomas Kuhn (1977), dada la «productividad» que usualmente arrojan las estrategias conservadoras de la «ciencia normal». En efecto, la innovación (más o menos creativa) implica la asunción de una serie de riesgos elevados y consiguientes castigos (Bourdieu 2008), sobre todo si no se cuenta con el suficiente capital científico como para afrontarlos. Esas estrategias innovadoras de alto riesgo pueden garantizar no sólo un alto impacto (habitualmente mayor que las contribuciones «conservadoras»), en concreto publicando y siendo citado, sino también el acceso a esa creatividad altamente apreciada en los campos científicos-académicos que puede llegar a garantizar un premio descollante o quedar registrado en la posteridad como un «clásico»o un autor de culto. Entre las fuerzas que detienen o estimulan esas estrategias de innovación, pueden operar constreñimientos institucionales (por ejemplo un departamento que ha practicado la acumulación del período de «ciencia normal»), aunque también las culturas disciplinares (Foster et. al, 2015). Por ello, es posible considerar ambos polos como «regiones distintas de posibles demandas de investigación o "tomas de posición". Los científicos anticipan un determinado perfil de riesgo y recompensa para cada región. A través de la elección de un problema de investigación, los científicos invierten en una particular mezcla de tradición e innovación» (Ibíd.: 878). 
Más allá de la dificultad para determinar con precisión cuán creativa e innovadora es una obra intelectual, la capacidad de influenciar a sus contemporáneos y a las generaciones sucesivas, es uno de los indicadores sustanciales. La historia de la ciencia en general y los diversos campos intelectuales puede considerarse, siguiendo a Collins (2002), como una historia de los grupos, de sus redes y sus rivalidades, en la que resulta esencial la conformación de redes intergeneracionales en torno a las cuales se concreten procesos de creatividad, es decir cadenas de alumnos y maestros, conformando un «campo estructurado de fuerzas» (Ibíd.) en el que además de esas cadenas intergeneracionales, se destacan las rivalidades contemporáneas.

Desde una perspectiva psicológica, Kasperson (1978) define a un científico creativo como alguien capaz de extraer información útil de las más diversas fuentes y que desarrolla una capacidad de producir «saltos» de conocimiento, por ejemplo produciendo teoría. El científico creativo aprovecha al máximo la energía emocional (Collins, 2002) y los rituales de interacción del campo científico, además de abrevar de fuentes de inspiración diversas y estar siempre abierto a los estímulos. La energía emocional fluye en situaciones en las que los individuos participan en rituales de interacción (congresos, clases, instancias de evaluación, conferencias, publicaciones) aunque también puede surgir en la soledad de los individuos. Los encuentros tienen consecuencias emocionales sobre todo cuando se fabrican los nodos de interacción, ya que la energía emocional decae en ciertos momentos y se recarga en cada interacción ritual. Pero la energía emocional no basta por sí misma, ya que necesita de un suficiente capital cultural o de una posición sólida en la red de una comunidad intelectual. Por eso es que «el entusiasmo creativo es más probablemente un preludio a las emociones frustradas y fallas de reconocimiento» (Ibíd.: 34). De ese modo, la energía emocional aumenta o disminuye a partir del éxito o fracaso en ese tipo de interacciones. En ese sentido, no debe soslayarse la relevancia de los contextos (por ejemplo institucionales) para la gestación de nuevas ideas como también que existan canales favorables de difusión (publicaciones científicas receptivas) y las mencionadas cadenas horizontales y verticales (densas redes disciplinares) que garanticen la exitosa circulación de esas nuevas ideas. En este marco, las mentes creativas requieren de innovaciones institucionales que les den sustento, ya que por lo general los sistemas 
científicos y académicos no tienden precisamente a favorecer las rupturas con los saberes aceptados.

La creatividad contempla la innovación, también la inventiva, la originalidad y el descubrimiento (Kasperson, 1978) pero sobre implica todo algún tipo de modificación estructural del orden usual de las cosas. Todo ello redundaría en obtener resultados distintivos de los que dominan el presente en los respectivos ámbitos de actuación disciplinar. En esta línea, tiene sentido la figura del científico productivo (no creativo), que trabaja bajo los parámetros «correctos» que «las cómodas rutinas del pensamiento que la vida académica promueve y respalda» (Becker, 2009: 22), es decir, siguiendo las tradiciones de investigación bajo las que se formó y se desempeña, fortaleciendo de ese modo los mandatos de la «ciencia normal». Tal vez, nuestras instituciones científicas y cierto habitus imperante en las ciencias sociales argentinas tiendan a favorecer prácticas endogámicas de grupos «consolidados» que se autovalidan. $\mathrm{Y}$ aunque si bien el «descubrimiento» de nuevos objetos suele cosechar buenos resultados (por ejemplo, ser considerado el «pionero» y hasta el «dueño» de un objeto), diferente es lo que ocurre cuando la innovación y la creatividad atentan contra las prácticas «correctas» que legitiman objetos, enfoques y ciertas prácticas científicas protegidas, aquellos lugares comunes de la investigación que estimulan la comodidad y las zonas de confort.

En las ciencias sociales, la creatividad entendida en esos sentidos muestra procesos ambivalentes, dado que una obra intelectual puede tener una elevada capacidad de influenciar las cadenas horizontales (por ejemplo, las modas académicas) mientras que otros legados tardan décadas o hasta algún siglo en provocar un impacto significativo en un campo disciplinar específico. Uno de los ejemplos más notorios del primer caso tal vez sea Norbert Elias (1897-1990), a quien el reconocimiento académico le llegó de manera tardía, recién en el crepúsculo de su vida. Otros autores, por ejemplo Gabriel Tarde (1843-1904), si bien no fueron completamente olvidados, no pudieron influenciar a sus contemporáneos ni construir poderosos discipulados, pero alrededor de un siglo después de su muerte se constituyó en una referencia obligada de líneas de investigación que han producido importantes innovaciones en la teoría social contemporánea, como la teoría del actor-red 
propuesta por Bruno Latour o las posiciones englobadas en lo que se ha denominado "giro ontológico" en antropología.

En el período considerado en este artículo, pueden encontrarse diversas estrategias de innovación (y eventualmente con elevadas cuotas de creatividad) que siguieron algunos de los principales referentes de las ciencias sociales argentinas. Se trató de una época en la que precisamente no podía hablarse de una «ciencia normal», ni siquiera en la antropología, la disciplina social que había alcanzado hacia mediados del siglo XX el mayor grado de institucionalización. Entonces, en este texto se presentarán cuatro «casos» asociados a dos disciplinas, antropología (Alberto Rex González y Marcelo Bórmida) y sociología (Gino Germani y el colectivo autodefinido como sociología nacional). De esa manera se analizarán situaciones en donde se produjeron indudables innovaciones y que, con mayor o menor creatividad, dejaron huellas dispares en las ciencias sociales argentinas.

\section{Gino Germani, entre el eclecticismo teórico y la innovación institucional}

Como en muchos otros contextos nacionales periféricos, las ciencias sociales en la Argentina se caracterizaron por un pluralismo teórico que en algunos casos remitía a definiciones conceptuales y epistemológicas aparentemente incompatibles. En ese sentido, un ejemplo paradigmático y también notorio es Gino Germani. Como referente de la sociología científica y fundador de la carrera de sociología de la Universidad de Buenos Aires (UBA), adhería, a grandes rasgos, al estructural-funcionalismo norteamericano. Sin embargo, evidenció una mayor amplitud teórica, con una trayectoria académica caracterizada por estudios que ponían un énfasis notorio en los aspectos sociohistóricos de las sociedades latinoamericanas y las dinámicas psicosociales en los procesos de cambio, lo que favoreció una coincidencia programática con el enfoque desarrollista de organismos como la Comisión Económica para América Latina (CEPAL) (Blanco, 2006; Suasnábar, 2004). Inclusive, como ha mostrado Blanco (2006), las inquietudes analíticas de Germani estuvieron influenciadas también por distintos teóricos de la Escuela de Frankfurt, por el destacado sociólogo de origen húngaro Karl Mannheim y por la psicología social, además 
de su continuo diálogo intelectual y proyectos conjuntos (por ejemplo en los estudios sobre inmigración en la Argentina) con el historiador José Luis Romero.

Más allá de que la producción académica de Germani es en sí misma -además de voluminosa- descollante, tal vez el mayor legado de su obra no descanse precisamente en las explicaciones e interpretaciones propuestas a través de sus estudios empíricos, en particular sobre la Argentina (como su interpretación del peronismo). Independientemente de cualquier debate teórico que excede a este artículo, Germani mostró otras facetas que excedieron su posición como investigador, configurando una labor intelectual que abarcó una intensa gestión editorial y, sobre todo, de creación institucional, tanto en la universidad pública como en el ámbito privado, como en el Instituto Torcuato di Tella (Blanco, 2006). De ese modo, ejerció un liderazgo (burocrático, intelectual) que le permitió controlar espacios relevantes en la academia argentina, además de los recursos económicos que gestionó exitosamente en esos ámbitos, principalmente los provenientes de la fundaciones filantrópicas norteamericanas (Gil, 2011). En ese contexto se rodeó de un grupo de jóvenes que, con diversas formaciones de grado, se transformarían en referentes descollantes de la sociología argentina por varias décadas. Ese grupo de «jóvenes y brillantes contertulios» (Horowicz, 2007: 143) accedió a la posibilidad, propiciada por Germani, de realizar posgrados en el extranjero en las tradiciones metropolitanas, práctica poco habitual en las ciencias sociales argentinas de la época. Además, el propio Germani estimuló el desarrollo de investigaciones empíricas de largo alcance sobre la sociedad argentina, que llegaron incluso a generar una alarma por parte de la jerarquía eclesiástica, que paradójicamente también favoreció el florecimiento institucional de la sociología a partir de la creación de carreras de grado, por ejemplo en las diversas sedes de la Universidad Católica Argentina (UCA) y en la Universidad del Salvador.

En definitiva, sin pretender ser demasiado exhaustivo sobre el caso de Germani ya que se trata de una figura estudiada por otros autores, ${ }^{2}$ nos encontramos frente a un actor

\footnotetext{
${ }^{2}$ Tanto la trayectoria de Germani como el período que protagonizó el sociólogo italiano en la Argentina ha merecido numerosos y completos estudios (Blanco, 2006; Noé, 2005; Pereyra, 2007 y 2010). Inclusive se cuenta con una biografía escrita por su hija Ana (Germani, 2004), sólidamente documentada e ilustrativa sobre su trayectoria intelectual.
} 
descollante en el campo científico. Protagonista y líder de innovaciones significativas, se propuso colocar a la sociología argentina en el marco de los más rigurosos estándares internacionales. Más allá del relativo escaso tiempo con el que contó (poco menos de 10 años) para llevar adelante su proyecto intelectual, los resultados fueron notorios. En pocos años, la carrera de sociología de la UBA contaba con un plantel de profesores con formación de posgrado en centros de excelencia del exterior, y con destacadas figuras internacionales como profesores visitantes. Entre otros aspectos, desde el Centro de Investigaciones Sociológicas, que también dirigía Germani en el Instituto Torcuato di Tella, se editaba una revista de referencia en el continente (Revista Latinoamericana de Sociología). Esa nueva disciplina se convirtió además no sólo en una elección masiva de los jóvenes universitarios (y no tan jóvenes) sino que logró una notoriedad pública jamás vista. Esto último posibilitó que el saber sociológico se incorporara de manera sistemática en organismos estatales e internacionales de planificación y gestión. Según Pereyra (2010), Germani constituye un ejemplo de cómo «los intelectuales pueden lograr reconocimiento y prestigio porque son capaces de imponer sus propios criterios de legitimación, aplicar estrategias de autopromoción, utilizar eficientemente las estructuras institucionales y usar ciertas habilidades gerenciales y empresariales» (Ibíd.: 37). Pero su proyecto de sociología «normal», con un alto impacto de la teoría de matriz parsoniana, terminó naufragando en la mitad de la década de 1960. Las condiciones heterónomas del campo intelectual hicieron imposible la continuidad de ese proyecto académico de definitiva institucionalización disciplinar, en un marco de rupturas políticas (en particular los golpes de estado) que impidieron cualquier tipo de estabilidad institucional.

\section{La sociología nacional y la crítica al cientificismo}

Un legado indirecto (o tal vez, no deseado) de Germani lo constituye la sociología nacional. Como proyecto de construcción de una ciencia nacional, y en el marco de la radicalización y fragmentación del campo intelectual argentino y latinoamericano, esta sociología nacional repudió los parámetros dominantes del quehacer científico en ciencias sociales. La mayor parte de los referentes de esta corriente se formaron como sociólogos en 
la era germaniana en la UBA y rechazaron de manera tajante los parámetros teóricos, éticos e ideológicos que sustentaron su formación de grado. Luego del golpe militar de 1966 y las intervenciones en las universidades nacionales (en el marco de una renuncia generalizada del cuerpo de profesores, sobre todo en la UBA), un conjunto de sociólogos, adherentes mayormente al peronismo y a ciertas vertientes del catolicismo fueron designados directamente por el rectorado de la intervenida UBA, dándole forma a las cátedras nacionales en cuyo marco se plasmó de forma sistemática el proyecto sociología nacional. Esta corriente se propuso «crear nuevos enunciados y categorías teóricas que permitiesen generar propuestas no sólo para comprender sino, sobre todo, para transformar la realidad nacional» (Buchbinder, 2005: 197). En ese sentido, las ciencias sociales en el país experimentaron con mayor vigor una directa influencia de esos procesos políticos en el marco de los que comenzó a concebirse a la universidad - y por ende a todas las disciplinascomo un instrumento más para lograr la «liberación nacional». Gran parte de las críticas llevadas adelante por aquella sociología nacional giraban en torno a la utilización de la ciencia, sus objetivos ocultos y el destino de los resultados. Todo ellos fueron críticos ejes de debate, atravesados en gran medida por el mencionado accionar de las fundaciones filantrópicas (en especial la Fundación Ford) y sus políticas de financiamiento a la investigación científica, que jamás dejaron de estar en el centro de la polémica.

En oposición a la también autodenominada sociología cientifica que lideraba Gino Germani, los referentes de esta sociología nacional rechazaron las formas convencionales de entender la práctica científica. En esa sintonía, las teorías provenientes de los centros metropolitanos de producción de conocimiento fueron impugnadas de manera tajante, en especial el estructural-funcionalismo, aunque tampoco el marxismo escaparía de esas impugnaciones. La sociología nacional también retomó los cuestionamientos que desde las ciencias exactas, en particular el matemático Oscar Varsavsky (1920-1976), se habían formulado hacia el cientificismo. Este investigador cumplió una notoria labor en consolidar la crítica a ciertos mecanismos del campo académico y la idea de un desarrollo científico vinculado estrechamente con los intereses nacionales. Sus contribuciones impactaron fuertemente en ideas tales como el «científico latinoamericano», guiado por su creatividad y un «espíritu nacional», es decir, dedicado a resolver grupalmente y no de forma 
individual asuntos problemáticos en la sociedad en la que vive, rechazando las imposiciones y criterios internacionales acerca de qué y cómo se debe investigar. Según Varsavsky (1994), la actitud cientificista es la de aquel investigador que relega sus deberes sociales por privilegiar su carrera, cuestionando severamente la idea de una «ciencia universal».

En el ámbito de la sociología nacional, una de las figuras salientes fue Roberto Carri. Este sociólogo graduado en la UBA postulaba una ciencia social comprometida, revolucionaria, a la que colocaba del lado de un pensamiento nacional como opuesto a una sociología antinacional. Carri optaba por un método "histórico global" a partir del cual, en consonancia con los argumentos de la historia revisionista, contraponía dos políticas, una nacional y otra antinacional, una de ellas favorable a un desarrollo productivo autóctono y otra a la expansión del imperialismo y la dependencia. En esa línea, colocaba a la sociología científica como una mera reproductora de ese patrón de pensamiento y posicionamiento ideológico, porque preserva el sistema y no lo transforma. Se refería entonces a un "falso rigor cientificista" que trata de contener la inevitable lucha "contra la dominación extranjera y oligárquica, el fundamento de una sociedad nueva" (Carri, 1970: 148). Por ello, entendía que la historia nacional debe definir la tarea de la ciencia social que, en la búsqueda de la conciencia nacional, ${ }^{3}$ se enfrenta al imperialismo para concebir las herramientas para la construcción de una sociedad nueva, vinculándola así al conocimiento colectivo de los pueblos. Por ello, aparece con frecuencia la antinomia del pensamiento social argentino versus el pensamiento imperialista. Este último, es caracterizado por un elevado carácter ideológico que se oculta en el poder imperial y que construye un sistema científico que despoja al pueblo de su verdadero poder. Esa historia nacional está entonces protagonizada por las fuerzas sociales que sistemáticamente defendieron la autonomía nacional, las masas populares, las economías del interior, todo ello para construir una Argentina "unida y soberana” (Ibíd.: 151).

\footnotetext{
${ }^{3}$ La obra de Juan José Hernández Arregui es una referencia impostergable de ese pensamiento nacional. Para este autor, el peronismo y su base proletaria y provinciana era una de las fuerzas que representa lo nacional, como continuidad de las montoneras y los caudillos federales. La crítica de Hernández Arregui apuntaba a la penetración imperialista y «la conciencia antinacional de las clases colonizadas», combatidas históricamente por fuerzas con conciencia nacional y origen nativo como el peronismo, genuino representante del «proletariado industrial y rural».
} 
En sus intervenciones en revistas paradigmáticas de la época en la segunda mitad de la década del sesenta, como Antropología del Tercer Mundo (de ahora en adelante ATM), Carri solía abordar recurrentemente estos tópicos en los cuales la problemática del cientificismo era dominante. En el primer número de $A T M$ de noviembre de 1968, Carri ligó directamente el cientificismo con la ideología desarrollista, a la que calificaba como la variante local y sociológica del neoimperialismo, por estar "siempre ligada estrechamente a un orden estatal, sin Estado no hay Sociología. Al invalidar las supuestas separaciones entre conocimiento y práctica, y entre ciencia y sociedad, Carri cargaba contra la práctica convencional del científico:

porque se vive a sí mismo como científico individual o a lo sumo integrado a la comunidad de científicos. Por lo tanto, su vinculación con la exterioridad se produce a través de la elaboración de recetas técnicas para que la sociedad o sus líderes no actúen. No hay integración del conocimiento con la praxis, por tanto no hay conocimiento real. O mejor dicho, hay conocimiento burgués (Carri, 1968: 2).

El marxismo tampoco quedaba indemne de los cuestionamientos, ya que si bien constituyó una fuente inspiradora para muchos de estos autores, en última instancia no dejaba de representar al cientificismo universalista que se consideraba dominante. Además de barrera para analizar y operar sobre nuestra realidad, diversos sociólogos nacionales también le adjudicaban al marxismo haber sido utilizado como un arma contraria a los intereses del pueblo, como lo parecían confirmar las variantes marxistas vernáculas que se habían opuesto al peronismo por "no entenderlo". Por ejemplo, Juan Pablo Franco cuestionaba al marxismo a causa de su vocación universalizante nacida por fuera del Tercer Mundo. De esta manera, equiparaba la "sociología crítica" (el marxismo) con la «sociología académica» (el estructural-funcionalismo), dado que ambos eran favorables a la aceptación de:

elementos científicos universales y postulan solamente la crítica a una utilización ideológica que tergiversa esos principios universales del método científico. En última instancia dejan incuestionada a la "ciencia", al 
método científico, a la realidad institucional y cultural heredada, a ese producto histórico que es la sociología (Franco, 1970: 120).

Aquel anticientificismo militante redundó, en líneas generales, en un conjunto de postulados de dudosa solidez teórica, que mezclaba categorías nativas, categorías descriptivas y categorías analíticas, montándose en cuestionamientos hacia las tradiciones clásicas, que fueron vaciadas de contenido y analizadas casi exclusivamente desde una dimensión ideológica. Sin haber llegado tampoco a desarrollar trabajos empíricos de ninguna clase, propusieron una visión estilizada de la participación popular, de la trayectoria de la resistencia peronista y del propio «pueblo» al que sentían representar, pero al que de alguna manera pretendían concientizar para la lucha revolucionaria. Deben sumarse a ello los análisis de la historia y realidad social argentina que se asentaban en antinomias esquemáticas en las cuales el peronismo (presentado casi sin fisuras) era presentado como un movimiento de masas revolucionario que contenía, en su asociación con los intereses del pueblo, un conjunto de afirmaciones de una verdad indiscutible. La intervención en el campo de las ciencias sociales se concretó, entonces, a partir de una propuesta diferente de ciencia que en este caso supeditaba la validez del conocimiento a la concreción de los objetivos revolucionarios

\section{La antropología de mitad de siglo: entre lo «nuevo» y lo «viejo»}

Décadas después del período caracterizado por las figuras salientes de Juan Bautista Ambrosetti (1865-1917) y su discípulo Salvador Debenedetti (1884-1930), la antropología argentina de mediados del siglo XX estaba hegemonizada por la Escuela Histórico-Cultural (EHC) de raiz germana. Ello fue en gran parte posible a partir del liderazgo ejercido por el italiano José Imbelloni (1885-1967). Esa EHC alemana había perdido -casi por completorelevancia en el campo antropológico mundial, más allá de que algunos de sus postulados seguían parcialmente vigentes en una de las tres principales tradiciones metropolitanas como el culturalismo boasiano que hegemonizaba la disciplina en los Estados Unidos. Los referentes locales de EHC consideraban la disciplina antropológica dentro de los 
parámetros filosóficos del historicismo y rechazaban tajantemente los enfoques (neo)evolucionistas y funcionalistas, estos últimos por la fuerte impronta sociológica en sus planteos.

La hegemonía de esta matriz de pensamiento comenzó a sufrir algunos embates a mediados del siglo XX, en especial por la labor renovadora de un joven arqueólogo formado en el departamento de antropología de la Universidad de Columbia: Alberto Rex González. Graduado como médico en la Universidad Nacional de Córdoba, González realizó estudios de posgrado en los Estados Unidos desde 1949, y a su regreso a la Argentina comenzó a construir una trayectoria político-académica opuesta -aunque no siempre conflictiva- con el mainstream de la antropología argentina de la época. Ya asentado en el país, González logró insertarse dentro del "ciclo de credibilidad" (Latour \& Woolgar, 1986) en la arqueología argentina, publicando asiduamente, incluso en las revistas que controlaba el grupo liderado por Imbelloni, como el caso de Runa. Archivo para las Ciencias del Hombre. De hecho, sus primeras publicaciones no contienen demasiadas referencias teóricas que polemizaran con los postulados teóricos dominantes. No por ello, esas producciones se privaban de formular observaciones críticas, en especial en los aspectos metodológicos. Pero su capital científico comenzó a incrementarse una vez que rompió con ese ciclo de credibilidad original y tuvo la posibilidad de hacer valer en el campo de la antropología argentina la confiabilidad de sus datos, sus credenciales académicas y sus soportes institucionales y fuentes de financiamiento. Así, pudo tejer una sofisticada red de alianzas cada vez más sólida y completa que le permitiría ocupar cargos en diversas universidades, construir compactos discipulados, presidir comisiones y reuniones científicas de relevancia y posicionarse como un actor central en la arqueología argentina, pero también como una referencia impostergable para quienes se volcarían por la todavía incipiente subdisciplina de la antropología social en los años sesenta.

Progresivamente, los métodos empleados por González entraron en tensión con los postulados aceptados mayoritariamente en el campo antropológico argentino. En principio, la utilización sistemática de la estratigrafía y el empleo "revolucionario" del fechado radiocarbónico, configuraron "una nueva etapa para la arqueología en la Argentina" (Pérez 
Gollán, 1998: 18), que empezaría a incorporar preocupaciones y conceptos de la corriente histórico-cultural norteamericana (Politis 2001), como el de área cultural, las tipologías y las influencias ambientales. Entonces, la noción de área cultural -ampliamente desarrollada por su profesor en Columbia, Julian Steward- comenzó a cumplir un papel relevante en las interpretaciones, descripciones y clasificaciones, ya que se ponía el énfasis en la relación de las respectivas poblaciones con su medio ambiente, considerada esa vinculación más directa en aquellas culturas de menor desarrollo (González \& Pérez Gollán, 1972). Ello no excluía, en esta concepción, la existencia de un gran centro de irradiación de civilización: el «Centro Nuclear Andino». Aunque para muchos arqueólogos no están demasiado claros los fundamentos neoevolucionistas en gran parte de los trabajos de González, nunca dejó de afirmar que su búsqueda analítica fue siempre la "evolución cultural". Mucho tiempo después de su formación en Columbia, González seguía confiando en que "la idea de Evolución y la explicación de sus mecanismos es uno de los objetivos fundamentales de la ciencia" (González, 1998: 364). Así, le adjudicaba a la complejidad de la cultura la imposibilidad de haber encontrado todavía explicaciones análogas a las de evolución biológica.

El vínculo entre las subdisciplinas antropológicas que propició González se sostendría en una obra enfocada a mostrar que es «posible buscar una interpretación integral de la cultura sin perder por ello el rigor en el nivel más básico de descripción arqueológica o desatender el desarrollo de técnicas refinadas de recopilación e interpretación del material de campo tanto propio como ajeno» (Ceballos \& Hidalgo, 1998: 19). Las mismas autoras señalan que González desarrolló un proyecto «ambicioso» que giró en torno a tres dimensiones fundamentales: la relevancia de la investigación empírica; la utilización de nuevos y más rigurosos métodos y tecnologías; y «la articulación en explicaciones abarcativas y unificadas teóricamente» (Ibíd.: 1998: 20). Todo ello en pos de lograr una síntesis entre «una aproximación descriptiva (clasificaciones, tipologías, seriaciones) y una aproximación interpretativa o explicativa de escenarios históricos» (Ibíd.: 20). Precisamente, uno de los tantos «alumnos informales» de González, destaca en relación a su afiliación teórica adquirida en los Estados Unidos que el neoevolucionismo se ocupaba de los proesos contemporáneos, lo que permitía dirigir la mirada tanto a las sociedades campesinas como 
urbanas, además de contemplar la posibilidad de intervención de la antropología «en la resolución de problemas» (Ratier, 1998: 43).

Como aquí se sugiere y se ha trabajado con mucho mayor detalle en otros escritos (Gil, 2010; 2014), la labor renovadora de González no se reduce a la introducción de nuevas líneas teóricas -cuya firme adhesión tampoco es su características saliente- sino que se apoya en gran medida en un conjunto de rasgos que posibilitaron escapar de los dictados de un EHC y su aplicación local que retardaba cualquier actualización teórica y metodológica de la antropología argentina. Tanto por su labor arqueológica y sus innovadoras técnicas de investigación como por su liderazgo construido especialmente en diversas instituciones universitarias (Soprano, 2010), González se constituyó en un punto de referencia obligado para arqueólogos y antropólogos sociales que encontraron, en torno a su figura, a un actor fundamental para producir cambios en la densa red disciplinar de la antropología argentina. $\mathrm{Y}$ aunque las rupturas institucionales de tinte autoritario en la política nacional (sobre todo 1966, 1974 y 1976) produjeron procesos de desinstitucionalización que desestructuraron esos cambios progresivos, su legado nunca dejó de permanecer vigente.

\section{Bórmida y la etnología tautegórica}

Nacido en Italia, Marcelo Bórmida (1925-1978) es todavía un autor «maldito» en la antropología argentina. Durante mucho tiempo su sola mención despertaba severas condenas morales e ideológicas a causa de sus afiliaciones políticas y las cuotas de poder que ejerció en distintos momentos en la UBA y en el Consejo Nacional de Investigaciones Científicas y Técnicas (CONICET), particularmente en los momentos de rupturas políticas autoritarias, como 1966, 1974 y 1976. A sus imputadas inclinaciones fascistas, se sumaba la resistencia sistemática hacia la antropología social, la subdisciplina postergada en el país y su proyecto - poco antes de su muerte- de cierre de la carrera de ciencias antropológicas en la UBA, para que la disciplina volviera a ser una especialidad de la carrera de historia, y también una opción de postgrado (Ratier, 2010). Bórmida estudió ciencias biológicas en la Universidad de Roma, donde se formó con el raciólogo Sergio Sergi (Silla, 2012). Desde su radicación en la Argentina en 1946 estudió historia en la UBA, donde se vinculó con su 
connacional José Imbelloni. Adhirió tempranamente a la EHC, pero hacia mediados de 1960 comenzó a elaborar una propuesta teórica original (la etnología tautegórica) que a su modo anticipó debates hoy vigentes en la teoría social contemporánea, como lo ha demostrado Silla (2014). Sin embargo, como la parte «maldita» de la antropología argentina, todo aquello vinculado con Bórmida fue excluido de cualquier continuidad legítima y su obra quedó relegada a sus seguidores nucleados en el Centro Argentino de Etnología Americana (CAEA).

La temprana adhesión de Bórmida al difusionismo alemán y sus inquietudes analíticas -y tal vez ideológicas- por la problemática de las razas configurarían el principio de una trayectoria intelectual sensiblemente diferente a la que puede advertirse tras su conversión a la fenomenología al promediar la década de 1960 y sus trabajos de campo entre los ayoreo en el Chaco boreal. En efecto, Bórmida iría modificando paulatinamente sus principales esferas de interés. Los postulados difusionistas y sus inquietudes sobre la problemática racial irían desapareciendo de su obra a la par de que se interesaba más por los pueblos del presente y dejaba fluir fuentes intelectuales como Husserl, Vico, von Schelling, Cassirer, Gusdorf y el contemporáneo etnólogo italiano Ernesto de Martino (1908-1965). Según uno de sus primeros discípulos, Mario Califano (2003), a comienzos de la década del 1960 Bórmida se vio impactado por una diversidad de pensadores que lo alejaron del difusionismo, como los autores ya nombrados y los antropólogos franceses Lucien LévyBruhl (1957-1939) y Maurice Leenhardt (1878-1954). El propio Califano (2003) describe que la nueva orientación que siguió Bórmida comenzó a plasmarse en una serie de seminarios sobre "conciencia mítica" que se dictaron en la segunda mitad de los años sesenta. En esos cursos intentó sistematizar experiencias de campo previas (por ejemplo entre los «tehuelches meridionales») y contemporáneas al dictado de esos seminarios (entre los pilagá, mataco, toba, ayoreo, entre otros pueblos). Para la sistematización de la etnología tautegórica resultó fundamental la obra de Friedrich Wilhelm Joseph von Schelling (1775-1874), de quien tomó el rótulo tautegórico con el que definiría su propuesta etnológica (Silla, 2014). Según von Schelling, los mitos constituyen «hechos 
tautegóricos» dado que, lejos de suponer alegorías (por ejemplo, de la organización social), implican una verdad para la conciencia humana, es decir, deben ser explicados sin salir de ellos mismos, en su esencia. Como consecuencia, el enfoque tautegórico busca dar cuenta de la esencia del mito sin apelar a determinaciones históricas y psicológicas o buscar las causas y razones de su constitución.

Hacia finales de la década de 1960, comenzaron a aparecer los primeros artículos de Marcelo Bórmida, principalmente en Runa, que dan cuenta del giro hacia la fenomenología y el planteo de aquello que denominará etnología tantegórica (Silla, 2014; Bórmida, 196970). Aunque seguía interesándose por el mundo indígena americano, los pueblos «bárbaros», sus inquietudes analíticas se comenzaron a concentrar en torno a las mitologías. Esa fenomenología que proponía Bórmida consiste en primera instancia «en la intuición y en la enunciación sucesiva y ordenada de todo lo dado inmediatamente en los fenómenos que la constituyen, es decir, de todos los aspectos de sus hechos vividos» (Bórmida 1976: $36)$.

La fenomenología propuesta por Bórmida apunta al hecho vivido, es decir, a las vivencias que puedan traducirse «en ciencias, comportamientos, actitudes y emociones» (Bórmida 1976: 34). Por ende, consideraba al fenómeno cultural como «todo lo que se da inmediatamente en el hecho que se considera, cuando se lo intuye en su vivencia concreta como integrado por todo aquello que estructuralmente lo constituye» (Ibíd.: 34). Se trata entonces de un ejercicio metodológico que consiste en «intuir vivencias concretas y no rasgos esquemáticos y abstractos» (Ibíd.: 34). El intuir hechos de vida le permitía plantearse la garantía de captar lo «dado inmediatamente» (Ibíd.: 34) en vez de buscar sistematizaciones intelectualistas que se traduzcan en rasgos, estructuras y categorías. Argumentos conceptuales de estas características le servían a Bórmida para condenar la «etnografía tradicional» que pretende «explicar lo irracional de la cultura en términos racionalistas» (Ibíd.: 29). Según su óptica, este tipo de explicaciones proyecta una racionalidad inexistente sobre los hechos vividos, cuando lo que corresponde es entender sus sentidos y, como consecuencia, acceder a las «estructuras generales de existencia o esencias vivenciales» (Ibíd.: 30). 
Al colocar al hecho cultural vivido como la fuente de exploración del conocimiento antropológico, Bórmida pretendía suprimir la interferencia del observador, eliminando cualquier subjetividad que puede introducirse en el dato que conduzca, por ejemplo, «en ver más de lo que hay en las vivencias culturales, agregándoles algo que en ellas no existe» (Ibíd.: 30). El «hecho vivido» se refiere a los sentidos que se producen en los contenidos de conciencia:

en cuanto contenido de conciencia propio de una cultura: tanto sus aspectos de racionalidad conscientes como sus facetas irracionales; tanto su sentido pragmático como la actitud emocional con que se lo apercibe. Un arma no es solamente un artefacto y una técnica, sino puede ser también un factor de prestigio, un don de los antepasados, un reservorio de potencia, un ente temido (Ibíd.: 30).

En ninguno de sus textos Bórmida abundaba demasiado en sus fuentes teóricas para la construcción de su etnología tautegórica. Por supuesto mencionaba, aunque no lo citara sistemáticamente y de forma reiterada, al filósofo alemán Edmund Husserl. El concepto husserliano de reducción eidética es la clave conceptual de la propuesta teórica bormidiana, aunque previamente apelaba a epojé (o reducción fenomenológica). Como explicaba el mismo Bórmida, se hace necesario «reducir la actitud subjetiva, procedimiento en base al cual es posible intuir lo dado objetivamente en esas vivencias» (Ibíd.:36). Al excluir lo que procede del sujeto, el etnógrafo debe desplegar su intuición orientando «el conocimiento hacia la propia e inmediata vivencia del hecho cultural» (Ibíd.: 37), por lo que es necesario que el investigador se despoje de todo su conjunto de conocimientos previos. Esa posición supone entonces rechazar los «conceptos empíricos y abstractos» (Ibíd.: 52) que proceden de los enfoques sociologistas.

Las ocasionales revisiones de la obra de Bórmida han tendido a caricaturizar esta propuesta fenomenológica, cuestionándola además por las deficiencias de los trabajos de campo de sus discípulos. En esa línea, se ha puesto énfasis en el modo en que las investigaciones fenomenológicas locales más representativas le adjudican realidad a las interpretaciones postuladas por los sujetos de estudio (Tiscornia \& Gorlier 1984). Ello implicaría que ese 
«rechazo a toda explicación "intelectualista" en aras de una comprensión fenomenológica conduce a una suerte de apología de todo lo dicho por el informante» (Gordillo, 1996) o una «reproducción fiel; las operaciones reductoras que el etnógrafo realiza terminan sobrando» (Reynoso, 1998: 135), para lo que se necesita solamente de «un mecanismo de registro, de hecho, un grabador» (Ibíd.: 135).

\section{Conclusiones}

La condición periférica de las ciencias sociales argentinas jamás fue el campo propicio para la creación teórica. No sólo las limitaciones impuestas por la división internacional del trabajo científico imponen barreras elevadas, sino que tampoco las periferias suelen permitirse escapar de ese lugar subalterno. Pero por supuesto esas barreras no son infranqueables $\mathrm{y}$, por ejemplo, en una academia cercana desde lo geográfico como la brasileña, abundan casos de producción teórica original que tuvieron capacidad de posicionarse en los debates internacionales. Para la antropología de la época considerada en este artículo, tal vez el caso de Roberto Cardoso de Oliveira y su teoría de la etnicidad sea un caso particular de lo posible. Pero el contexto argentino muestra con crudeza un conjunto de limitaciones que excede la configuración internacional de los campos científicos. Su alto grado de heteronomía y las lógicas internas de los campos académicos contribuyeron a dinamitar proyectos académicos innovadores y también imposibilitaron el desarrollo de otras innovaciones, como la creación de postgrados, a causa de sus fuentes de financiamiento (las fundaciones filantrópicas) (Gil, 2011).

Las trayectorias presentadas constituyen ejemplos de desarrollos teóricos que dan cuenta del pluralismo teórico que imperó en las ciencias sociales argentinas en el contexto de su definitiva institucionalización y de gran parte de las dos décadas que le siguieron. Se trató de dispositivos enunciativos que se montaron en conversaciones (Collins, 2002) con ideas provenientes de diversos ámbitos, por lo general de las tradiciones centrales. En todos los casos, las ideas que sostuvieron estos dispositivos teóricos se materializaron (Rodríguez Medina, 2014) de manera particular e incluso en determinados momentos consiguieron regular algunos de los principales debates de esos campos disciplinares. Se trata de casos 
que muestran procesos creativos e innovadores que dejaron importantes huellas en las ciencias sociales argentinas. Pero sólo aquellos que fueron innovadores en materia de creación institucional y exitosos en la formación de discipulados influyentes (Germani y González) dejaron sus huellas explícitas, sus evidentes condiciones de reconocimiento, en sus respectivas disciplinas. Más allá de que no produjeron teorías y conceptos que dominen la discusión teórica contemporánea, se trata de obras y trayectorias legitimadas en sus respectivas afiliaciones disciplinares, aunque las de Germani mucho más cuestionadas que las de González.

Los otros dos «diálogos» fueron altamente desafiantes de las posiciones teóricas dominantes en el mundo de las ciencias sociales. Aunque en ambos casos dispusieron de un poderoso correlato institucional (cuyos detalles exceden el alcance de este artículo), mucho más perdurable en el caso de Bórmida, no lograron sostenerse en el mainstream de sus propias disciplinas. A contramano de los enfoques teóricos producidos en las tradiciones metropolitanas y barridos institucionalmente en diferentes rupturas políticas que impactaron en la universidad (1974-76 en el caso de la sociología nacional, la «primavera camporista» de 1973 y el regreso de la democracia en 1983 en el caso de Bórmida) jamás fueron retomados como parte del debate central en sus disciplinas. Mientras que la obra de Bórmida ha sido tenuemente recuperada como una anticipación (fuera de época y tal vez en mayor medida de contexto) de debates de plena actualidad en la teoría antropológica (Silla, 2014), el impacto de la sociología nacional tal vez pueda buscarse de forma mucho más indirecta y no tanto en la instauración de genealogías visibles o invisibles. Sin legitimidad explícita en las diferentes ciencias sociales, una parte importante de sus postulados y axiomas se mantienen como condiciones de producción en diferentes discursos sociales en nuestra contemporaneidad, presentes por ejemplo en cierto sentido común revisionista, en la discursividad política «populista», en publicaciones oficiales de organismos de cultura y hasta en la creación de organismo gubernamentales. 


\section{Bibliografía}

Becker, H. (2009). Trucos del oficio. Cómo conducir su investigación en ciencias sociales. Buenos Aires: Siglo XXI.

Blanco, A. (2006). Razón y modernidad. Gino Germani y la sociología en la Argentina. Siglo XXI: Buenos Aires.

Bórmida, M. (1969-70). Mito y cultura. Runa. Archivos para la ciencia del Hombre ( ${ }^{\circ}$ 12), 7-35.

Bórmida, M. (1976). Etnología y Fenomenología. Ideas acerca de una Hermenéutica del Extrañamiento. Buenos Aires: Ediciones Cervantes.

Bórmida, M. (2003). La conciencia mítica. Seminario. Archivos (n I): 21-212.

Bourdieu, P. (2008) Homo academicus. Buenos Aires: Siglo XXI.

Buchbinder, P. (2005). Historia de las universidades argentinas. Buenos Aires: Sudamericana.

Califano, Mario (2003). Apuntes biográficos del autor. Archivos (n I), 14-19.

Carri, R. (1968). El formalismo en las ciencias sociales. Antropología del Tercer Mundo. Revista de Ciencias Sociales 1 (1): 1-6.

Carri, R. (1970). Pensamiento nacional y sociología antinacional. En AA. VV., Ciencias Sociales: ideología y realidad nacional (pp. 143-165). Buenos Aires: Tiempo Contemporáneo.

Ceballos, R. e Hidalgo, C-. (1998). Alberto Rex González: la búsqueda de una interpretación integral de la cultura. En AA. VV., Homenaje a Alberto Rex González. 50 años de aportes al desarrollo y consolidación de la antropología argentina (pp. 19-24). Buenos Aires: Facultad de Filosofía y Letras, UBA.

Collins, R. (2002). The Sociology of Philosophies. A Global Theory of Intellectual Change. Cambridge: Belknap Press. 
Foster, J. et. al (2015). Tradition and Innovation in Scientists' Research Strategies. American Sociological Review 80 (5), 875-908.

Franco, J. (1970). Doctrina de la Liberación y Sociología Crítica. Antropología del Tercer Mundo. Revista de Ciencias Sociales 2 (6), 119-137.

Gil, G. (2010). Neoevolucionismo y ecología cultural. La obra de Julian Steward y la renovación de la enseñanza de la antropología en la Argentina. Revista del Museo de Antropología ( $\mathrm{n}^{\circ}$ 3), 225-238.

Gil, G. (2011). Las sombras del Camelot. La Fundación Ford y las ciencias sociales en la Argentina de los sesenta. Mar del Plata: EUDEM.

Gil, G. (2014). El carbono 14 en la antropología argentina. Ciencia, objetos y controversias disciplinares. En Guber, R. (comp.) Antropologías argentinas. Determinaciones, creatividad y disciplinamientos en el estudio nativo de la alteridad (pp. 199-249). Buenos Aires: Ediciones Al Margen.

Gordillo, G. (1996). Hermenéutica de la ilusión: la etnología fenomenológica de Marcelo Bórmida y su construcción de los indígenas del Gran Chaco. Cuadernos de Antropología Social (n ${ }^{\circ}$ 9), 135-171.

González, A. R. (1952). Antiguo horizonte precerámico en las Sierras Centrales de la Argentina. Runa ( $\left.{ }^{\circ} \mathrm{V}\right), 110-133$.

González, A. R. (1998). El rol de los sistemas simbólicos en el proceso de evolución cultural. En AA. VV., ob. cit., 363-378.

González, A. R. y Pérez Gollán, J. (2007). Argentina indígena. Visperas de la conquista. Buenos Aires: Paidós.

Horowicz, A. (2007). Sociología, 50 años en el ojo de la tormenta nacional. Revista Argentina de Sociología 5 (9), 136-152.

Kasperson, C. (1978) "Psychology of the Scientist: XXXVII. Scientific creativity: a relationship with information channels". Psychologicd Reports (n 42), 691-694. 
Kuhn, T. (1977) The Essential Tension: Selected Studies in Scientific Tradition and Change, Chicago: University of Chicago Press.

Latour, B. \& Woolgar, S. (1986) Laboratory Life. The construction of Scientific Facts. Princeton: Princeton University Press.

Noé, A. (2005) Utopía y desencanto. Creación e institucionalización de la Carrera de Sociología en la Universidad de Buenos Aires: 1955-1966. Buenos Aires: Miño y Dávila.

Pereyra, D. (2007) “Cincuenta años de la Carrera de Sociología de la UBA. Algunas notas contra-celebratorias para repensar la historia de la Sociología en la Argentina”. En Revista Argentina de Sociología 5 (9), 153-9.

Pereyra, D. (2010) "Los científicos sociales como empresarios académicos. El caso de Gino Germani". En Pereyra, D. (ed.), El desarrollo de las ciencias sociales. Tradiciones, actores e instituciones en Argentina, Chile, México y América Central, San José de Costa Rica.

Pérez Gollán, J. (1998) “La presencia de Alberto Rex González en la Universidad de Córdoba”. Estudios (n 10), 17-29.

Politis, G. (2001) "On Archaeological Praxis, Gender Bias and Indigenous Peoples in South America". En Journal of Social Archaeology 1(1), 90-107.

Ratier, H. (1998) "Alberto Rex González y la Antropología Social en la Argentina". En AA. VV., ob. cit., pp. 39-46.

Ratier, H. (2010) "La antropología social argentina: su desarrollo". En Publicar VII (IX), 17-46.

Reynoso, C. (1998) Corrientes en antropología contemporánea. Buenos Aires: Biblos.

Rodriguez Medina, L. (2014) "Construyendo periferia: un microanálisis de objetos subordinantes como tecnologías epistémicas". En Sociológica, 29 (83), 9-46.

Silla, R. (2012) "Raza, raciología y racismo en la obra de Marcelo Bórmida". En Revista del Museo de Antropología 5, 65-76. 
Silla, R. (2014) "Etnologia e fenomenologia. Um comentário as obras de Tim Ingold, Viveiros de Castro e Marcelo Bórmida". En Sociología \& Antropología 4 (2), 351-372.

Soprano, G. (2010) "La enseñanza de la arqueología en la Facultad de Ciencias Naturales y Museo de la Universidad Nacional de La Plata. Un análisis sobre el liderazgo académico de Alberto Rex González y Eduardo Mario Cigliano (1958-1977)”. En Revista del Museo de Antropología (n 3 ), 225-238.

Suasnábar, C. (2004) Universidad e intelectuales. Educación y política en la Argentina (1955-1976). Buenos Aires: FLACSO-Manantial.

Tiscornia, S. \& Gorlier, J. (1984) "Hermenéutica y fenomenología: exposición crítica del método fenomenológico de Marcelo Bórmida”. En Etnia 3 (1), 20-38.

Varsavsky, O. (1994) Ciencia, política y cientificismo. Buenos Aires: CEAL. 